\title{
PROCEDIMIENTOS INTERTEXTUALES EN LA OBRA DE BLAS DE OTERO
}

Lucía Montejo Gurruchaga

$U N E D$

El término intertextualidad se aplica al texto literario en el que se pueden leer discursos ajenos. En este concepto se ha visto el cauce para disipar tanta ambigüedad como implicaba la idea de influencia porque con la intertextualidad no se designa una adición confusa, imprecisa, de fuentes, de enlaces o ascendentes misteriosos, sino que se debe entender como la irrupción relevante de un texto en otro. El intertexto es, por tanto, la cita, alusión, parodia, sátira, recurrencia o repercusión de un texto ajeno (o propio, se trataría, entonces, de pseudocitas, autotextos o autoreferentes) que el creador inserta en su propio texto'.

Es evidente que no todos los textos presentan el mismo grado de intertextualidad; no siempre se trata de una cita precisa y fácilmente identificable (hay que tener en cuenta que la sensibilidad del lector, su cultura, pueden alterar el grado de explicitación de la intertextualidad), sino que, en ocasiones, el intertexto alude a una determinada estructura verbal, a una figura poética, a un paradigma genérico o a una estructura rítmica precisa.

Este es uno de los procedimientos que más llaman la atención en la obra de Blas de Otero. El poeta bilbaíno somete citas ajenas y propias a distintas manipulaciones, a distorsiones que pueden alterar, y de hecho siempre lo hacen, el significado del intertexto, e incluso invertir su significado. Si algo caracteriza a los procesos intertextuales es el trabajo de asimilación y transformación que el creador lleva a cabo.

Los procedimientos de intertextualidad se hacen patentes en la obra ote-

\footnotetext{
' Sobre el concepto de intertextualidad véase: Julia Kristeva, Semiótica, (Madrid: Ed. Fundamentos, $1981^{2}$ ), 189 y ss; sobre los usos de la intertextualidad: Claudio Guillén, Entre lo uno y lo diverso. Introducción a la literatura comparada, (Barcelona: Crítica, 1985), 309-327.
} 
riana desde el principio. (Ya en Cántico Espiritual hay un eco evidente de San Juan de la Cruz que se hace visible no sólo en citas textuales, sino en su vocabulario, símbolos y estructura ${ }^{3}$ ). Estos procesos intertextuales se producen por distintos caminos:

1. Alusión, parodia, ironía, cita de textos literarios cultos o de fuentes populares (como el Cancionero por vía popular o tradicional).

2. Modificación o ruptura de una frase hecha, refrán o dicho popular.

3. Inserción de autocitas (modificadas o no) para reforzar, o por el contrario, rechazar, una situación o actitud pasada.

En las líneas que siguen se verán ejemplos de estos procedimientos de intertextualidad en la obra de Blas de Otero.

En su libro en prosa Historias fingidas y verdaderas ${ }^{4}$, en el fragmento titulado Zortziko muestra su hostilidad hacia las manifestaciones que dicen ser poéticas y tienen como objetivo la creación de mundos de ficción y aboga, como en otras muchas ocasiones a lo largo de su obra, por una poesía con minúscula, que se interese por el hombre y su quehacer. Estas son sus palabras:

"Lo que yo no comprendo es cómo hay tantos poetas en el mundo. Pero dejemos esto. (Te hiciste cómplice, amigo, y llamaste poetas a los que escriben versos o algo parecido, para los que aquí en Cuba existe una palabra que encaja divinamente; pero dejemos esto, como es sabido el bestial elemento se solaza en el odio a la sacra Poesia - cito de memoria, de todas maneras esa mayúscula no hay quien la aguante).»

La cita que aparece en letra bastardilla corresponde a dos endecasilabos del poema IX de Rubén Darío, de Cantos de vida y esperanza $a^{5}$. Blas de Otero

2 Blas de Otero Muñoz: Cántico Espiritual, Cuardernos del grupo «Alea», núm. 2, 1." serie, (San Sebastián: Gráfico-Editora, 1942).

${ }^{3}$ En mi tesis doctoral, Teoria poética a través de la obra de Blas de Otero, (Madrid: Universidad Complutense, 1987), inédita, págs. 392-401, se muestran las distintas conexiones y el resultado al que llega Blas de Otero al aludir o incluir en el tejido de sus poemas, estructuras, palabras o citas de San Juan de la Cruz.

4 Blas de Otero: Historias fingidas y verdaderas, (Madrid-Barcelona: Alfaguara, 1970), 35.

s Rubén Darío: Cantos de vida y esperanza, (Madrid: Espasa-Calpe, 1980'4), 51. 
quiere denunciar con esta cita no el uso modernista de las mayúsculas, sino la sacralización del ente literario, el «arte por el arte».

Pero no es esta la única cita textual del fragmento. En el último parágrafo leemos:

"Sí, será mejor que cambiemos de tema, no vayas a caer en la trampa y no puedas desasirte en el tiempo que te queda, que ha ido menguando y apenas cabe en lo que aún tienes que decir, en verso o en chino, me es igual, lo que sé es que no me podrán quitar el dolorido (cito por experiencia) sentir si muero desterrado, pues no hay otro camino por donde mis razones vayan fuera que el camino de mi aldea, donde me salen siempre a recibir (cito de memoria) el aire de mis campos y el son del tamboril.»

Garcilaso en la Égloga $I^{6}$ había puesto las siguientes palabras en boca de Nemoroso:

«no me podrán quitar el dolorido

sentir si ya del todo

primero no me quitan el sentido»

(vv. 349-351)

Este moroso lamento del afligido amante sólo puede acallarlo la muerte. Sin embargo, Otero que vive entonces en $\mathrm{Cuba}^{7}$, como el desterrado pone su esperanza en la vuelta ligada a la belleza de la naturaleza de su paisaje natal. La añoranza de su patria chica queda reflejada en las tres últimas líneas del fragmento en prosa cuyas palabras corresponden, con leves modificaciones como se puede comprobar, a algunos versos de un conocidísimo zortziko, canción de tierras vascas, y título de la prosa, que dice exactamente:

"camino de mi aldea

me sale a recibir,

- Garcilaso de la Vega: Poesías castellanas completas, ed. de Elías L. Rivers, (Madrid: Castalia, $\left.1972^{2}\right), 131$.

${ }_{7}$ Blas de Otero permaneció en Cuba desde 1964 a 1968 en que vuelve definitivamente a España. Alli escribió su libro en prosa Historias fingidas y verdaderas. 
En los ejemplos de intertextualidad que se han visto, Blas de Otero no menciona la fuente de la que toma el discurso. Alerta al lector por medio de la letra bastardilla, en algunas ocasiones, de la inserción en sus palabras de un texto ajeno, pero, con frecuencia, asimila y transforma contenidos ya existentes en un proceso intertextual complejo. En la prosa que acabamos de ver, el texto literario aparece como una configuración abierta en la que se entrecruzan otros textos literarios y el cancionero tradicional. En los ejemplos que siguen se verán otras transformaciones intertextuales (siempre que un texto se inserta en otro sufre una transformación) aunque no de carácter literario.

En Esto no es un libro aparece el poema titulado «En un lugar de Castilla». Dice Otero:

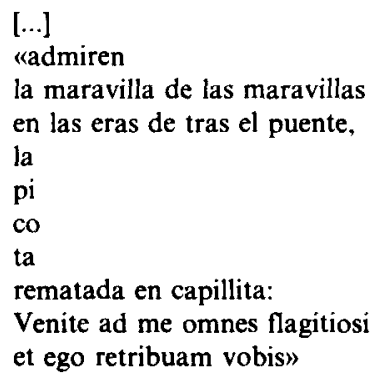

Se trata de una inscripción que aparece en una picota de Covarrubias (Burgos). Quiere poner el poeta de manifiesto la antinomia que se produce entre el significado de la inscripción y el lugar en que aparece, es decir, el pilón o columna que había en la entrada de los pueblos donde se exponía a los reos o las cabezas de los que habían sido ejecutados para que sirvieran de escarnio. El consuelo de los afligidos (¡con qué ironía lo incluye el poeta!) es la muerte.

- Blas de Otero: Esto no es un libro, (San Juan de Puerto Rico: Editorial Universitaria de Puerto Rico. Río Piedras, 1963), 45. El título está tomado de Walt Whitman. Otero abre este libro con la siguiente cita del poeta norteamericano: «...esto no es un libro. Quien vuelve sus páginas toca un hombre». 
El poeta bilbaíno utiliza la ironía con mucha frecuencia a lo largo de su obra. Se produce una ironía cuando un enunciado posee un sentido figurado opuesto a su sentido literal. El lector debe descifrar el mensaje y debe tener la capacidad de comprender la desviación de sentido que ha tenido lugar. En ocasiones, hay indicios contextuales que impregnan todo el texto y que ayudan a decodificar la ironía, como lo son ciertos modalizadores alusivos, pomposos o enfáticos, o una peculiar entonación o cambio de registro en la expresión. Pero, en ocasiones, la ironía no se trasluce con facilidad y puede tener un eco lejano e impreciso que hace nadar al lector en las aguas de la ambigüedad ${ }^{9}$ y, así ocurre, a veces, que sólo cuando se conoce a fondo la trayectoria creadora de alguien, se puede afirmar que hay ironía por sobreentendidos que se extraen del texto global.

La burla, la broma irónica, como se puede ver en el ejemplo que acabamos de apuntar, se manifiesta generalmente bajo formas de expresión elogiosas, bajo formas que implican buenas cualidades, pero, por el contrario, conllevan un juicio negativo.

Estos distintos procedimientos intertextuales (alusión, cita, parodia, anagrama, autoreferente, sátira, ruptura de frases hechas, etc.), se presentan, en ocasiones, en la obra oteriana, no de forma aislada, sino entrelazados, de manera que el texto se convierte en un diálogo intertextual entre distintos discursos asimilados y transformados ${ }^{10}$. El texto resultante entraña conceptos complejos, de marcadas acepciones simbólicas y con una forma condensada y depurada que implica e indica un lento proceso de gestación.

El anagrama es otro de los procedimientos de intertextualidad que utiliza Blas de Otero aunque no con la profusión de los anteriores. Se denomina anagrama a la transposición de los fonemas o de los grafemas de una palabra para construir otra. Generalmente no todos los anagramas son completos; es decir, en el anagrama no aparecen todas las letras del nombre al que remplaza. Lo importante es que el anagrama se aperciba como tal por-

- Sobre la ironía pueden verse los artículos siguientes: Dan Sperber y Deirdre Wilson: «Les ironies comme mentions", Poétique, 36, (1978), 399-412, y Catherine Kerbrat-Orechioni: «L'ironic comme trope», Poétique, 41, (1980), 108-127.

${ }^{10}$ Uno de los ejemplos más completos de cuanto acabamos de decir se encuentra en el poema "Retablo" que figura en Esto no es un libro, aunque es de la época de Redoble de conciencia, 1951. Es muy interesante ver el entretejimiento de referencias bíblicas, citas del Quijote, frases hechas y las sorprendentes desviaciones que sobre ellas hace el poeta. Hay una parodia mordaz y sarcástica de la Biblia, tanto del Apocalipsis como de los Hechos de los Apóstoles, 9 , y del Salmo 22 (17-18); referencias a Pilatos, e intercala, además, muy transformada, una larga cita del Quijote II, cap. XXVI, a la que corresponde también el título. Hay una desmitificación de la fe religiosa a la que el poeta alude utilizando el anagrama "zarandajas", cosas sin importancia de las que no merece la pena ocuparse, sobre el intertexto cervantino «Zaragoza». La desmitificación de la transcencia la lleva a cabo utilizando, además, transformado, el propio lenguaje religioso. 
que «le sens caché est le sens profond: l'anagramme révèle la nature secrète, ésotérique, et "donc» la vraie nature du sujet qu'il predique»".

El poema "La casa a oscuras», incluido en Esto no es un libro" ${ }^{12}$, comienza con este verso:

\section{"Unúrsil viene de dar la mano a un niño»}

El poeta siente la necesidad de disfrazar, de ocultar, por medio del anagrama, el nombre del lugar en el que estuvo retirado un año víctima de una tremenda depresión. Se trata del sanatorio psiquiátrico de Usúrbil, localidad guipuzcoana.

Para terminar nos detendremos brevemente en las autocitas o autoreferentes. Blas de Otero recurre con bastante frecuencia a sus versos anteriores y con la nueva inclusión suele apuntalar una situación pasada o marcar el cambio que se ha operado en su vida o en su obra. En "Cartas y poemas a Nazim Hikmet», incluido en En Castellano ${ }^{13}$, dice:

"Soy sólo poeta, pero en serio,"

Este verso lo retomará, con ligeras variantes, en dos poemas de su libro Que trata de España ${ }^{14}$. Con esta autocita quiere reafirmar su dedicación; ésta fue su única profesión y a ella se entregó de modo exclusivo.

Estos recursos intertextuales en Blas de Otero son, en ocasiones, homenaje y señal de admiración y gratitud hacia determinados poetas con los que comparte problemas de orden estético o con los que tiene una filiación ideológica. Pero la mayoría de las citas que incorpora a sus poemas son de indole estética y con ellas establece lazos solidarios, polemiza o critica el ideario del poeta al que hace referencia.

"Francis Goyet: «La preuve par l'anagramme», Poétique, 46 (1981), 236.

12 Blas de Otero: Esto no es un libro, op. cit., 117.

"Blas de Otero: Parler Clair (En castellano), ed., bilingüe. Traducida del español y prologada por Claude Couffon, (París, Pierre Seghers, 1959).

14 Blas de Otero: Que trata de España. (Paris: Ruedo Ibérico, 1964). Se trata de "C.L.I.M.» y «Noticias de todo el mundo", 54 y 47. 
El complejo juego de voces ajenas, el denso grado de intertextualidad que refleja la obra de este poeta, es fruto de un lento proceso de asimilación y transformación que no sólo no disminuyen su identidad poética, sino que aportan un nuevo placer a la percepción de su palabra. 